\title{
Risk factors of gestational diabetes mellitus in Wuhan city of China--a case control study
}

\author{
Jianqiong Liu ${ }^{1}$, Qiong Dai ${ }^{1 *}$, Mei Yang ${ }^{2}$ and Yukai $\mathrm{Du}^{3}$ \\ ${ }^{1}$ Department of Child Health Care, Hubei Maternal and Child Health Hospital, Wuhan city, Hubei province, 430070, China \\ ${ }^{2}$ School of Public Health, Wuhan University of Science and Technology, Wuhan city, Hubei province, 430065, China \\ ${ }^{3}$ Department of Maternal and Children Health Care and Adolescent Hygiene, School of Public Health, Tongji Medical College, Huazhong University of Science \\ and Technology, Wuhan city, Hubei province, 430030, China
}

\begin{abstract}
Objective: To explore the main risk factors of gestational diabetes mellitus in Wuhan, China.

Methods: 206 women with gestational diabetes mellitus who were diagnosed in Hubei Maternal and Child Health Hospital between January 2014 and December 2015 were selected as case group. Meanwhile, 286 healthy pregnant women, who were delivered at the same time, were selected as control group. Maternal age, occupation, race/ethnicity, gestation status, and family history, etc. were obtained from the face-to-face interviews as well as their medical records. Univariate logistic regression analysis and multivariate logistic regression analysis were conducted to explore the risk factors.
\end{abstract}

Results: The factors included into multivariate logistic regression model were maternal age, menarche age, history of menstrual cycle disorder, spontaneous abortion frequency, maternal history of diabetes, and paternal history of diabetes. The Odds Ratios $(95 \% \mathrm{CI})$ were $1.50(1.14 \sim 2.04), 0.36(0.16 \sim 0.84), 3.85(1.59 \sim 9.36)$, $3.00(1.56 \sim 5.77), 3.89(1.15 \sim 13.17)$ and $6.54(2.42 \sim 17.69)$, respectively.

Conclusion: The risk factors of gestational diabetes mellitus were advanced maternal age, history of menstrual cycle disorder, spontaneous abortion frequency, maternal history of diabetes, and paternal history of diabetes, while advanced menarche age was a protective factor for gestational diabetes mellitus.

\section{Introduction}

Gestational diabetes mellitus (GDM), defined as carbohydrate intolerance at onset of pregnancy (or first recognition), affects about $4-7 \%$ of pregnancies overall [1-5]. A lot of researches (Kim, 2002; Metzger, et al., 2008) indicate that women with GDM have increased risk for perinatal morbidity [6,7] and a considerably elevated risk of impaired tolerance and Type 2 diabetes in the years after pregnancy $[8,9]$. Hillier, et al. (2007) has reported that children of women with GDM are more likely to be obese and suffer from impaired glucose tolerance and diabetes in childhood and early adulthood [8]. In addition, findings from in vivo and animal studies demonstrated that hyperglycemia during pregnancy had an adverse impact on embryogenesis as early as the preimplantation stages of development $[10,11]$. Collectively, these data highlight the significance of understanding risk factors for GDM and preventing GDM among high-risk populations.

Recent data show that GDM prevalence has increased by 10 $100 \%$ in several race/ethnicity groups during the past 20 years [1]. Unquestionably, there are ethnic differences in the prevalence of GDM [12-16]. In USA, Asians, Native Americans, Hispanics, and African American women are at higher risk for GDM than non-Hispanic white women [12-14]. In Australia, GDM prevalence has been reported (Beischer, 1991) to be higher in women whose country of birth is China or India than in women whose country of birth is in Europe or Northern Africa [15]. In Europe, GDM has been found to be more common among Asian women than among European women [16].

In conclusion, it is critical to find out the risk factors of Asian women to allocate appropriate resources to perinatal management and postpartum diabetes prevention strategies. However, there were only a few studies reporting the prevalence and risk factors of GDM in China $[17,18]$. Of particular note, the studies towards the central and western regions of China were lacked. As is well known, Wuhan is the largest metropolis in central China. Moreover, it is an important scientific education base of China. The total number of college students and graduate students has reached 107.26 million by the end of 2013 . Therefore, we conducted this study to explore the risk factors of GDM in Wuhan, in order to allocate appropriate resources to perinatal management and postpartum diabetes prevention strategies, so as to improve the physical quality of the whole population.

\section{Materials and methods}

\section{Diagnostic criteria}

According to the new criteria [19] by International Association of Diabetes and Pregnancy Study Groups (IADPSG), each woman at $24 \sim 28$ gestational week was evaluated with the 75 -g oral glucose tolerance test (OGTT): fasting glucose $\sim 5.1 \mathrm{mmol} / \mathrm{l}, 1-\mathrm{h} \sim 10 \mathrm{mmol} / \mathrm{l}$, or 2 -h $\sim 8.5 \mathrm{mmol} / \mathrm{l}$. If any one of the above three indicators of the

Correspondence to: Qiong Dai, Department of Child Health Care, Hubei Maternal and Child Health Hospital, Wuhan city, Hubei province, 430070, China, E-mail: daiqiong74@163.com

Key words: gestational diabetes mellitus, risk factors, logistic regression model Received: May 20, 2017; Accepted: June 12, 2017; Published: June 15, 2017 
pregnant woman reached or exceeded the critical value, she was diagnosed as GDM.

\section{Selection of case group and control group}

A total of 206 women with gestational diabetes mellitus who were diagnosed in Hubei Maternal and Child Health Hospital between January 2014 and December 2015 were selected as case group. Women with preexisting diabetes were excluded. Meanwhile, 286 healthy women without GDM who were delivered at the same time as the case group were selected as control group. The women in control group were neither with GDM nor with gestational impaired glucose tolerance. Similarly, women with preexisting diabetes were excluded too. Informed consents were obtained from all the participants.

\section{Data collection and analysis}

Face-to-face interviews were conducted in the in-patients settings in the above mentioned hospital. Interviewers were trained in survey and mental assessment methods. The same interviewer interviewed both cases and the matched controls to reduce information bias. Information on demographic characteristics (ethnicity, residence, and occupation), marital and reproductive history, medical history, and family history of GDM was ascertained directly from the subjects. In the meantime, we checked their medical records to ensure the information was consistent.

The collected information was uniformly coded and input into database with Epidata 3.1. All analyses were conducted using SPSS version 16.0. All data was presented as mean \pm standard deviation (SD) and analyzed by Student $t$ tests (for continuous data) and $\chi^{2}$ tests (for categorical data) to assess differences between the case and control groups. Univariate and multivariate logistic regression were used to compute odds ratio (OR) and $95 \%$ confidence intervals (CI). As the major objectives of our analysis was to identify a set of risk factors independently associated with the risk for GDM, explanatory variables that were associated with GDM in the univariate analyses were selected for inclusion in multivariate regression models. All tests of statistical significance were two sided, and statistical significance was defined at the $\mathrm{a}=0.05$ level.

\section{Results}

Demographic characteristics of the case group and control group were showed in Table 1. The average age of case group and control group was $30.76 \pm 4.30$ and $28.87 \pm 3.77$ years old, respectively. All the participants were native Chinese and were married. There were no statistical differences between case group and control group concerning race, domicile place, occupational status ( $P s>0.05)$.

We used univariate logistic regression analysis to screen potential risk factors of GDM. Table 2 presented that there were statistical differences concerning menarche age, menstrual cycle disorder history, parity, spontaneous abortion history, spontaneous abortion frequency, family history of diabetes, first pregnancy age, and pregnancy age this time between case group and control group $\left(\mathrm{Ps}_{\mathrm{s}}<0.05\right)$. On the contrary, the two groups had no statistical differences with regard to gravidity, induced abortion history, hypertension history, family history of malignant tumors (Ps>0.05).

Furthermore, we conducted multivariate logistic regression analysis on the variables that were statistically different in the univariate logistic regression analysis.

The factors finally brought into the model were pregnancy age this time, menarche age, menstrual cycle disorder history, spontaneous
Table 1. Demographic characteristics of the case group and control group

\begin{tabular}{|c|c|c|c|c|}
\hline Variables N (\%) & Case $(n=206)$ & Control( $\mathrm{n}=286)$ & $? 2$ values & $\mathrm{P}$ values \\
\hline \multicolumn{5}{|l|}{ Age (years) } \\
\hline $21 ?$ & $20(9.71 \%)$ & $30(10.49 \%)$ & & \\
\hline $25 ?$ & $62(30.10 \%)$ & $150(52.45 \%)$ & & \\
\hline $30 ?$ & $82(39.81 \%)$ & $82(28.67 \%)$ & & \\
\hline \multirow{2}{*}{$35 ?$} & $42(20.39 \%)$ & $24(8.39 \%)$ & & \\
\hline & & & 15.628 & 0.001 \\
\hline \multicolumn{5}{|l|}{ Race } \\
\hline Han & $204(99.03 \%)$ & $286(100.0 \%)$ & & \\
\hline \multirow[t]{2}{*}{ Others } & $2(0.97 \%)$ & $0(0.00 \%)$ & & \\
\hline & & & 1.39 & 0.238 \\
\hline \multicolumn{5}{|l|}{ Domicile place } \\
\hline City & $174(84.47 \%)$ & $236(82.52 \%)$ & & \\
\hline \multirow[t]{2}{*}{ Countryside } & $32(15.53 \%)$ & $50(17.48 \%)$ & & \\
\hline & & & 0.17 & 0.69 \\
\hline \multicolumn{5}{|l|}{$\begin{array}{c}\text { Occupational } \\
\text { status }\end{array}$} \\
\hline Worker/Farmer & $30(14.56 \%)$ & $20(6.99 \%)$ & & \\
\hline Service staff & $36(17.47 \%)$ & $58(20.28 \%)$ & & \\
\hline $\begin{array}{l}\text { Administrative } \\
\text { staff }\end{array}$ & $52(25.24 \%)$ & $74(25.87 \%)$ & & \\
\hline $\begin{array}{c}\text { Scientific/ } \\
\text { technical } \\
\text { personnel }\end{array}$ & $50(24.27 \%)$ & $82(28.67 \%)$ & & \\
\hline \multirow[t]{2}{*}{ Others } & $38(18.46 \%)$ & $52(18.19 \%)$ & & \\
\hline & & & 4.06 & 0.397 \\
\hline
\end{tabular}

abortion frequency, maternal history of diabetes and paternal history of diabetes, as shown in Table 3. The Odds Ratios (95\%CI) were 1.50 $(1.14 \sim 2.04), 0.36(0.16 \sim 0.84), 3.85(1.59 \sim 9.36), 3.00(1.56 \sim 5.77)$, 3. $89(1.15 \sim 13.17)$ and $6.54(2.42 \sim 17.69)$, respectively.

\section{Discussions}

The etiology of GDM is multi-source, which is the reciprocal action of genetic factors and social environmental factors. In our study, we found that advanced maternal age, maternal history of diabetes and paternal history of diabetes were strongly associated with an elevated risk of GDM, with OR $(95 \% \mathrm{CI})$ at $1.50(1.14 \sim 2.04), 3.89(1.15 \sim 13.17)$ and $6.54(2.42 \sim 17.69)$, respectively. This finding was consistent with previous studies $[17,18]$. In addition, spontaneous abortion frequency and history of menstrual cycle disorder were significantly associated with an elevated GDM risk. On the contrary, advanced menarche age might be a protective factor for GDM.

The association of a history of spontaneous abortion with GDM risk has not been widely studied. Our findings presented a positive association of impaired glucose tolerance in pregnancy with a history of spontaneous abortion or recurrent spontaneous abortion. Moreover, for gestational women, the risk of suffering from GDM would elevate as the spontaneous abortion frequency increase (OR 3.00; 95\%CI 1.56 $\sim 5.77$ ). We speculated that such an association was at least in part because of common risk factors or shared pathological mechanisms of spontaneous abortion and GDM. For instance, in a cohort study (Tian, 2007) of Chinese women undergoing infertility treatment, insulin resistance, which was a key component of the pathogenesis of GDM, was a strong independent risk factor of spontaneous abortion [20]. The underlying biological mechanisms for such an association, however, are still unclear and warrant further investigations.

Multivariate logistic regression analysis revealed that a history of irregular menses was a risk factor for the onset of GDM, and the OR value was 3. 99 (95\% CI 1. $64 \sim 9.64)$. The results were consistent with 
Table 2. Univariate logistic regression analysis of risk factors to GDM

\begin{tabular}{|c|c|c|c|c|}
\hline Variables N (\%) & Case $(n=206)$ & Control(n=286) & ?2 values & P values* \\
\hline \multicolumn{5}{|l|}{ Age (years old) } \\
\hline $11 ? 14$ & $186(90.29)$ & $234(81.82)$ & & \\
\hline \multirow[t]{2}{*}{$? 14$} & $20(9.71)$ & $52(18.18)$ & & \\
\hline & & & 6.761 & 0.009 \\
\hline \multicolumn{5}{|l|}{$\begin{array}{l}\text { Menstrual cycle } \\
\text { disorder history }\end{array}$} \\
\hline No & $176(85.44)$ & $272(95.10)$ & & \\
\hline \multirow[t]{2}{*}{ Yes } & $30(14.56)$ & $14(4.90)$ & & \\
\hline & & & 13.745 & 0.0002 \\
\hline \multicolumn{5}{|l|}{ Parity } \\
\hline 0 & $148(71.84)$ & $238(83.22)$ & & \\
\hline \multirow[t]{2}{*}{$1 ?$} & $58(28.16)$ & $48(16.78)$ & & \\
\hline & & & 9.162 & 0.0025 \\
\hline \multicolumn{5}{|l|}{$\begin{array}{c}\text { spontaneous } \\
\text { abortion history }\end{array}$} \\
\hline No & $166(80.58)$ & $270(94.41)$ & & \\
\hline \multirow[t]{2}{*}{ Yes } & $40(19.42)$ & $16(5.59)$ & & \\
\hline & & & 22.684 & $? 0.001$ \\
\hline \multicolumn{5}{|l|}{$\begin{array}{l}\text { spontaneous } \\
\text { abortion } \\
\text { frequency }\end{array}$} \\
\hline 0 & $166(80.58)$ & $270(94.40)$ & & \\
\hline $1 ? 2$ & $36(17.48)$ & $12(4.20)$ & & \\
\hline \multirow[t]{2}{*}{$3 ?$} & $4(1.94)$ & $4(1.40)$ & & \\
\hline & & & 24.446 & $? 0.001$ \\
\hline \multicolumn{5}{|l|}{$\begin{array}{c}\text { Family history } \\
\text { of diabetes }\end{array}$} \\
\hline No & $158(76.70)$ & $272(95.10)$ & & \\
\hline \multirow[t]{2}{*}{ Yes } & $48(23.30)$ & $14(4.90)$ & & \\
\hline & & & 36.834 & $? 0.001$ \\
\hline \multicolumn{5}{|l|}{$\begin{array}{l}\text { First pregnancy } \\
\text { age(years old) }\end{array}$} \\
\hline $20 ?$ & $42(20.39)$ & $58(20.28)$ & & \\
\hline $25 ?$ & $74(35.92)$ & $152(53.15)$ & & \\
\hline $30 ?$ & $68(33.01)$ & $68(23.78)$ & & \\
\hline \multirow[t]{2}{*}{$35 ?$} & $22(10.68)$ & $8(2.80)$ & & \\
\hline & & & 23.63 & $? 0.001$ \\
\hline \multicolumn{5}{|l|}{$\begin{array}{l}\text { Pregnancy age } \\
\text { this time(years } \\
\text { old) }\end{array}$} \\
\hline $20 ?$ & $20(9.71)$ & $30(10.49)$ & & \\
\hline $25 ?$ & $62(30.10)$ & $150(52.45)$ & & \\
\hline $30 ?$ & $82(39.81)$ & $82(28.67)$ & & \\
\hline \multirow[t]{2}{*}{$35 ?$} & $42(20.39)$ & $24(8.39)$ & & \\
\hline & & & 31.257 & $? 0.001$ \\
\hline
\end{tabular}

GDM: gestational diabetes mellitus; *All the factors in this table were statistical different $(P$ values $<0.05)$

Table 3. Multivariate logistic regression analysis of risk factors to GDM

\begin{tabular}{|c|c|c|c|c|c|c|}
\hline Risk factors & $?$ & SE & $? 2$ values & P values & OR & $95 \%$ CI \\
\hline Pregnancy age this time & 0.42 & 0.18 & 5.59 & 0.018 & 1.5 & $1.14 ? 2.04$ \\
\hline Menarche age & -0.5 & 0.25 & 3.99 & 0.046 & 0.36 & $0.16 ? 0.84$ \\
\hline Menstrual cycle disorder history & 0.68 & 0.27 & 6.25 & 0.012 & 3.85 & $1.59 ? 9.36$ \\
\hline Spontaneous abortion frequency & 1.1 & 0.4 & 7.65 & 0.006 & 3 & $1.56 ? 5.77$ \\
\hline Maternal history of diabetes & 0.68 & 0.37 & 3.35 & 0.067 & 3.89 & $1.15 ? 13.17$ \\
\hline Paternal history of diabetes & 0.94 & 0.3 & 9.62 & 0.002 & 6.54 & $2.42 ? 17.69$ \\
\hline
\end{tabular}

GDM: Gestational Diabetes Mellitus; OR: Odds Ratio; CI: Confidence Intervals

the findings of the study of Haver et al. in 2003 [21], but inconsistent with some studies in mainland. The formation of the menstrual cycle depends on the neuroendocrine function coordination under hypothalamic - pituitary - ovarian axis. The estrogen and progestin secreted by ovary directly affect the menstrual cycle. Patients with menstrual cycle disorders have long been exposed to the effects of irregular secretions of estrogen and progesterone, which may affect the occurrence of GDM. Besides, maternal polycystic ovary syndrome (PCOS), including menstrual dysfunction, infertility, hirsutism, acne, obesity, and metabolic syndrome, have been reported to have an established increased risk of developing type 2 diabetes and an increased risk of hyperinsulinemia, insulin resistance, dyslipidemia and glucose intolerance $[22,23]$. We hypothesized that irregular menstrual cycles could be an effective, albeit imperfect, marker for GDM because of its routine documentation on prenatal history forms and its probable association with PCOS. We did not, however, quantify the number of bleeding episodes as some pregnant women could not recall the precise information of menstrual cycle. Nevertheless, we believe a history of irregular cycles before pregnancy may be a predictor for GDM that is independent of other traditional risk factors. If a limited screening approach for GDM ever gains widespread support, we suggest that women with irregular cycles be tested for GDM. Additionally, prospective studies should be considered to assess the value of screening these women for GDM in early pregnancy.

Furthermore, our study indicated that advanced menarche age was a protective factor for GDM. In a cohort study conducted by Lakshman et al. (2008), they found that earlier age at menarche is associated with increased risk of type 2 diabetes. The current finding, an association between earlier menarche and adult diabetes that was attenuated by adult BMI, might therefore be indicative of a risk pathway beginning with rapid infant weight gain and continuing with childhood-onset of overweight and obesity, and adult obesity. Alternatively, earlier rate of pubertal development might itself lead to differences in adiposity during adolescence and adulthood. With the development of society and economy in China, the age at menarche of girls has decreased steadily and it is unclear whether the secular trend in menarche age coincides with increasing rates of diabetes.

In our study, we have tried to reduce sampling bias by selecting control group who delivered at the same time and lived in the same room with the case group, and by making an initial contact with participants in the obstetric ward so that losses and refusals were reduced to a minimum. To reduce reporting and measurement bias, we adopted face-to-face interviewing as well as extracting from medical records, so as to make sure the information was consistent. However, our study has some limitations. First, the study was conducted in hospital. Although our hospital own the most deliveries in Hubei province, the selection bias may still exist. Second, the participants were asked to recall previous history, the recall bias might exist, though we adopted several methods to obtain information to minimize the bias. We will conduct prospective study to further identify these risk factors in future.

\section{Conclusion}

In summary, our study provides convincing evidence that advanced maternal age, family history of diabetes are strongly associated with an elevated risk for GDM in Wuhan city of China. In addition, history of spontaneous abortion, menstrual cycle disorder and earlier menarche onset appeared to be novel risk factors of GDM among these Chinese women. By ascertaining history of the above-mentioned factors, it may be possible to identify women with increased risk of pregnant gestational diabetes, in order to allocate appropriate resources to perinatal management and postpartum diabetes prevention strategies. 


\section{Authorship and contributorship}

All the authors listed meet the under conditions: 1) substantial contributions to conception and design, or acquisition of data, or analysis and interpretation of data; 2) drafting the article or revising it critically for important intellectual content; 3 ) final approval of the version to be published; 4) agreement to act as guarantor of the work. Jianqiong Liu and Qiong Dai contributed equally to this work.

\section{Acknowledgments}

Special thanks go to all the pregnant women who participated in the study. We appreciate all the colleagues who helped us to conduct the study. Meanwhile, we associate Professor Wang Ping for revising the manuscript.

\section{Competing interests}

The authors declare that there are no conflicts of interests (political, personal, religious, ideological, academic, intellectual, commercial or any other) in relation to this manuscript.

\section{References}

1. Ferrara A, Kahn HS, Quesenberry CP, Riley C, Hedderson MM. (2004) An increase in the incidence of gestational diabetes mellitus: Northern California, 1991-2000. Obste Gynecol 103:526-533. [Crossref]

2. Dabelea D, Snell-Bergeon JK, Harts?eld CL, Bischoff KJ, Hamman RF, McDuf?e RS. (2005) Increasing prevalence of gestational diabetes mellitus (GDM) overtime and by birth cohort: Kaiser Permanente of Colorado GDM Screening Program. Diabetes Care 28: $579-584$.

3. American Diabetes Association. Gestational diabetes mellitus (Position Statement). (2000) Diabetes Care 23 (Suppl. 1): S77-S79.

4. King H (1998) Epidemiology of glucose intolerance and gestational diabetes in women of childbearing age. Diabetes Care 21 Suppl 2: B9-13. [Crossref]

5. Kjos SL, Buchanan TA (1999) Gestational diabetes mellitus. N Engl J Med 341: 17491756. [Crossref]

6. Kim C, Newton KM, Knopp RH (2002) Gestational diabetes and the incidence of type 2 diabetes: a systematic review. Diabetes Care 25: 1862-1868. [Crossref]

7. HAPO Study Cooperative Research Group1, Metzger BE, Lowe LP, Dyer AR, Trimble ER, et al. (2008) Hyperglycemia and adverse pregnancy outcomes. N Engl J Med 358: 1991-2002. [Crossref]

8. Hillier TA, Pedula KL, Schmidt MM, Mullen JA, Charles MA et al. (2007) Childhood obesity and metabolic imprinting: the ongoing effects of maternal hyperglycemia. Diabetes Care 30: 2287-2292. [Crossref]
9. Bellamy L, Casas JP, Hingorani AD, Williams D. (2009) Type 2 diabetes mellitus after gestational diabetes: a systematic review and meta-analysis. Lancet 373: 1773-1779. [Crossref]

10. Moley KH (1999) Diabetes and preimplantation events of embryogenesis. Semin Reprod Endocrinol 17: 137-151. [Crossref]

11. Moley KH, Chi MM, Mueckler MM. (1998) Maternal hyperglycemia alters glucose transport and utilization in mouse pre-implantation embryos. Am J Physiol 275: E38E47. [Crossref]

12. Ferrara A, Hedderson MM, Quesenberry CP, Selby JV (2002) Prevalence of gestational diabetes mellitus detected by the national diabetes data group or the carpenter and coustan plasma glucose thresholds. Diabetes Care 25: 1625-1630. [Crossref]

13. Montana Department of Public Health and Human Services Chronic Disease Prevention and Health Promotion Program: Trends in Pregnancy Among American Indian and White Mothers in Montana 1989-2003. April to June 2005, 1-8

14. Thorpe LE, Berger D, Ellis JA, Bettegowda VR, Brown G et al. (2005) Trends and racial/ethnic disparities in gestational diabetes among pregnant women in New York City, 1990-2001. Am J Public Health 95: 1536-1539 [Crossref]

15. Beischer NA, Oats JN, Henry OA, Sheedy MT, Walstab JE. (1991) Incidence and severity of gestational diabetes mellitus according to country of birth in women living in Australia. Diabetes 40(Suppl.2): 35-38. [Crossref]

16. Dornhorst A, Paterson CM, Nicholls JS, Wadsworth J, Chiu DC, et al. (1992) High prevalence of gestational diabetes in women from ethnic minority groups. Diabet Med 9: 820-825. [Crossref]

17. Yang X, Hsu-Hage B, Zhang H, Yu L, Dong L, et al. (2002) Gestational diabetes mellitus in women of single gravidity in Tianjin City, China. Diabetes Care 25: 847 851. [Crossref]

18. Yang H, Wei Y, Gao X, Xu X, Fan L, et al. (2009) Risk factors for gestational diabetes mellitus in Chinese women: a prospective study of 16,286 pregnant women in China. Diabet Med 26: 1099-1104. [Crossref]

19. International Association of Diabetes and Pregnancy Study Groups Consensus Panel. International Association of Diabetes and Pregnancy Study Groups recommendation on the diagnosis and classi?cation of hyperglycemia in pregnancy. (2010) Diabetes Care 33: 676-682

20. Tian L, Shen H, Lu Q, Norman RJ, Wang J. (2007) Insulin resistance increases the risk of spontaneous abortion after assisted reproduction technology treatment. J Clin Endocrinol Metab 92: 1430-1433. [Crossref]

21. Haver MC, Locksmith GJ, Emmet E (2003) Irregular menses: an independent risk factor for gestational diabetes mellitus. Am J Obstet Gynecol 188: 1189-1191. [Crossref]

22. Norman RJ, Dewailly D, Legro RS, Hickey TE (2007) Polycystic ovary syndrome. Lancet 370: 685-697. [Crossref]

23. Ehrmann DA (2005) Polycystic ovary syndrome. N Engl J Med 352: 1223-1236. [Crossref]

24. Lakshman R, Forouhi N, Luben R, Bingham S, Khaw K, et al. (2008) Association between age at menarche and risk of diabetes in adults: results from the EPIC-Norfolk cohort study. Diabetologia 51: 781-786. [Crossref]

Copyright: (C2017 Liu J. This is an open-access article distributed under the terms of the Creative Commons Attribution License, which permits unrestricted use, distribution, and reproduction in any medium, provided the original author and source are credited. 